\title{
EL DERECHO DE ACCESO A LA JUSTICIA DE LAS VÍCTIMAS DE VIOLACIONES DE DERECHOS HUMANOS EN PERÚ: LA CORTE INTERAMERICANA DE DERECHOS HUMANOS ANTE EL INDULTO DE ALBERTO FUJIMORI
}

The right to access. to justice of victims of violations of human rights in Peru: the Inter-American Court of Human Rights with regard to Alberto Fujimori's pardon

\author{
AGATA SERRANÒ \\ Centro de Estudios Políticos y Constitucionales
}

agata.serrano@cepc.es

Cómo citar/Citation

Serranò, A. (2021)

El derecho de acceso a la justicia de las víctimas de violaciones de derechos humanos en Perú: la Corte Interamericana de Derechos Humanos ante el indulto de Alberto Fujimori. Anuario Iberoamericano de Justicia Constitucional, 25(2), 485-511. doi: https://doi.org/10.18042/cepc/aijc.25.15

\section{Resumen}

Este artículo se propone abordar la falta de tutela del derecho de acceso a la justicia de las víctimas del periodo de violencia que interesó el Perú desde 1980 a 2000, durante el cual tanto grupos terroristas como agentes del Estado perpetraron graves violaciones de derechos humanos. Después de describir los patrones de victimización de las desapariciones forzadas y ejecuciones extrajudiciales cometidas, se examinarán los innumerables tentativos para obtener impunidad por parte de los responsables de las masacres de Barrios Altos y La Cantuta, por las cuales el expresidente Alberto Fujimori fue antes condenado, luego indultado y, finalmente, tal indulto le fue revocado, mediante un control de convencionalidad. En conclusión, se pondrá en evidencia cómo el control de convencionalidad está logrando fijar estándares de tutela de los 
derechos de las víctimas de la violencia padecida en la región, favoreciendo la consolidación de un ius constitutionale commune promovido por la Corte IDH.

\section{Palabras clave}

Corte Interamericana de Derechos Humanos; indulto; delitos de lesa humanidad; justicia de las víctimas; control de convencionalidad; Perú.

\section{Abstract}

This article aims to address the lack of protection of the right to access to justice for victims of the period of violence 1980-2000 in Peru, during which both terrorist groups and State agents perpetrated serious violations of human rights. After describing the patterns of victimization of forced disappearances and extrajudicial executions committed, this article will focus on the countless attempts to obtain impunity by those responsible for Barrios Altos and La Cantuta massacres, for which former president Alberto Fujimori was previously convicted, then pardoned and, finally, such pardon was revoked, through a conventionality control procedure. In conclusion, how conventionality control procedure, promoted by the Inter-American Court of Human Rights, is favouring the consolidation of a ius constitutionale commune, setting standards for the protection of the rights of victims of violence, which interested Latin America, will be highlighted.

\section{Keywords}

Inter-American Court of Human Rights; pardon; crimes against humanity; justice for victims; conventionality control procedure; Peru. 


\section{SUMARIO}

I. ALGUNAS DE LAS HERIDAS VIVAS DE LAS VIOLACIONES DE DERECHOS HUMANOS EN PERÚ: LAS EJECUCIONES EXTRAJUDICIALES Y LAS DESAPARICIONES FORZADAS EN CIFRAS. II. LOS INNUMERABLES INTENTOS DE CONSEGUIR LA IMPUNIDAD EN LOS CASOS BARRIOS ALTOS Y LA CANTUTA. III. LA REVOCACIÓN DEL INDULTO A ALBERTO FUJIMORI. EL ROL FUNDAMENTAL DE LA CORTE IDH EN LA TUTELA DEL DERECHO DE ACCESO A LA JUSTICIA DE LOS FAMILIARES DE LAS VÍCTIMAS Y EN LA CONSOLIDACIÓN DEL IUS CONSTITUTIONALE COMMUNE MEDIANTE EL CONTROL DE CONVENCIONALIDAD. IV. CONCLUSIONeS. Bibliografía. Artículos y noticias de periódicos. Artículos de opINIÓN. INFORMES. JURISPRUDENCIA. TRATADOS INTERNACIONALES.

\section{ALGUNAS DE LAS HERIDAS VIVAS DE LAS VIOLACIONES DE DERECHOS HUMANOS EN PERÚ: LAS EJECUCIONES EXTRAJUDICIALES Y LAS DESAPARICIONES FORZADAS EN CIFRAS}

Entre 1980 y 2000 el Perú vivió un periodo de violencia sin precedentes, conocido más comúnmente como conflicto armado interno, que causó al menos 69.280 víctimas mortales, según la estimación de la Comisión de la Verdad y Reconciliación (CVR), creada en 2001 para esclarecer tales hechos (Degregori, 2014). Como se puede apreciar en el gráfico 2, los responsables de las víctimas causadas en Perú de 1980 a 2000 fueron grupos subversivos como Sendero Luminoso - SL (54\%) y el Movimiento Revolucionario Túpac Amaru - MRTA (1\%), las fuerzas de policía (6\%), las fuerzas armadas (30\%), los comités de autodefensa y las rondas campesinas - CADS (2\%), entre otros actores (7\%).

Tales actores durante el periodo de violencia - vivido durante los gobiernos de Belaunde Terry (1980-1985), Alan García (1985-1990) y Alberto Fujimori (1990-1995; 1995-2000; 2000-2000) — cometieron numerosas violaciones de los derechos humanos, tales como asesinatos, masacres, ejecuciones extrajudiciales, desapariciones forzadas, torturas y otros tratos crueles, inhumanos o degradantes, secuestros, violaciones sexuales, esterilizaciones forzadas, entre otras. Aunque todas las violaciones cometidas resultan de extrema gravedad y relevancia, en esta sede se abordarán especialmente los patrones de victimización y el modus operandi que se llevaron a cabo para efectuar las desapariciones forzadas y las ejecuciones extrajudiciales, puesto que son los delitos que se cometieron en los casos de Barrios Altos y La Cantuta, objeto de estudio de este artículo. Las 
desapariciones forzadas y las ejecuciones extrajudiciales (delitos inequivocablemente interconectados, puesto que las personas desaparecidas, en la mayoría de los casos, terminaron siendo ejecutadas arbitrariamente), como comprobaremos a lo largo de este artículo, fueron prácticas sistemáticas y generalizadas, llevadas a cabo especialmente por los agentes del Estado, cuyo fin fue eliminar físicamente a quienes consideraban ser subversivos.

Gráfico 1. Número de víctimas mortales por año según responsables principales

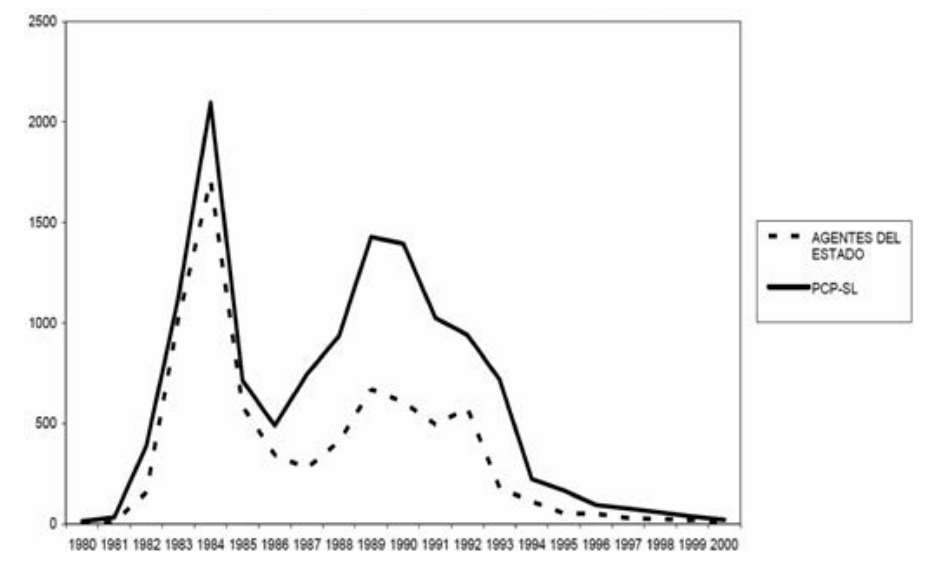

Fuente: Informe Final de la CVR, Las ejecuciones arbitrarias, 2003: 138.

Gráfico 2. Porcentaje de víctimas causadas por responsable

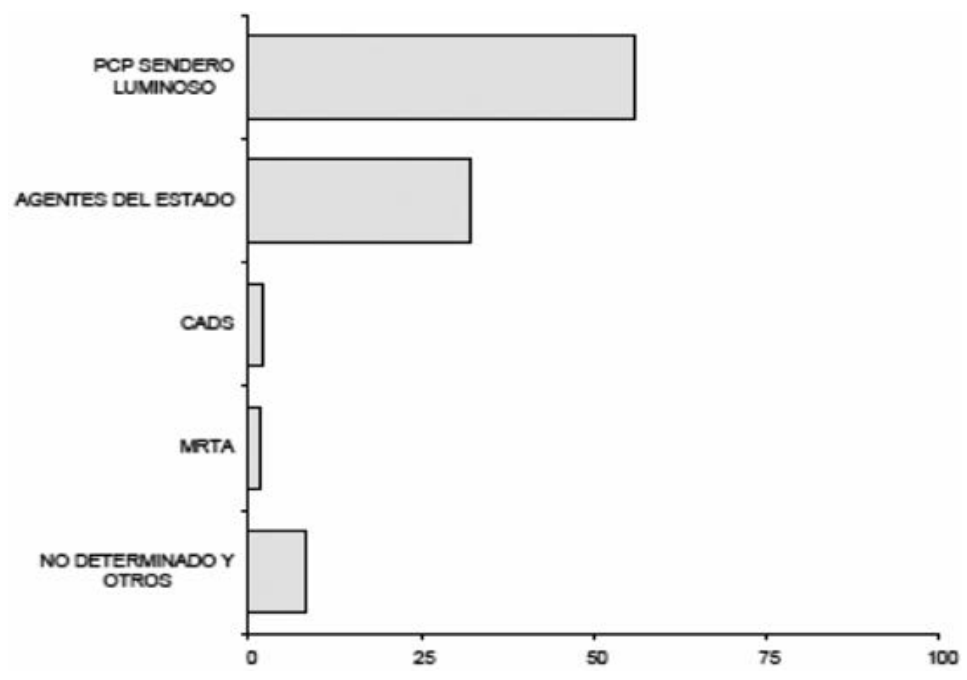

Fuente: Compendio estadístico (Anexo 3) del Informe Final de la CVR, 2003: 21-22. 
Por lo que se refiere a las ejecuciones extrajudiciales, fueron definidas por la CVR como «los homicidios, individuales o colectivos, perpetrados por agentes del Estado, fuerzas privadas, particulares, grupos paramilitares u otras fuerzas bajo su control, por orden de un gobierno o con su complicidad, tolerancia o aquiescencia fuera de un proceso judicial» (CVR, Las ejecuciones arbitrarias, 2003: 129).

Gráfico 3. Porcentaje de ejecuciones extrajudiciales según responsable

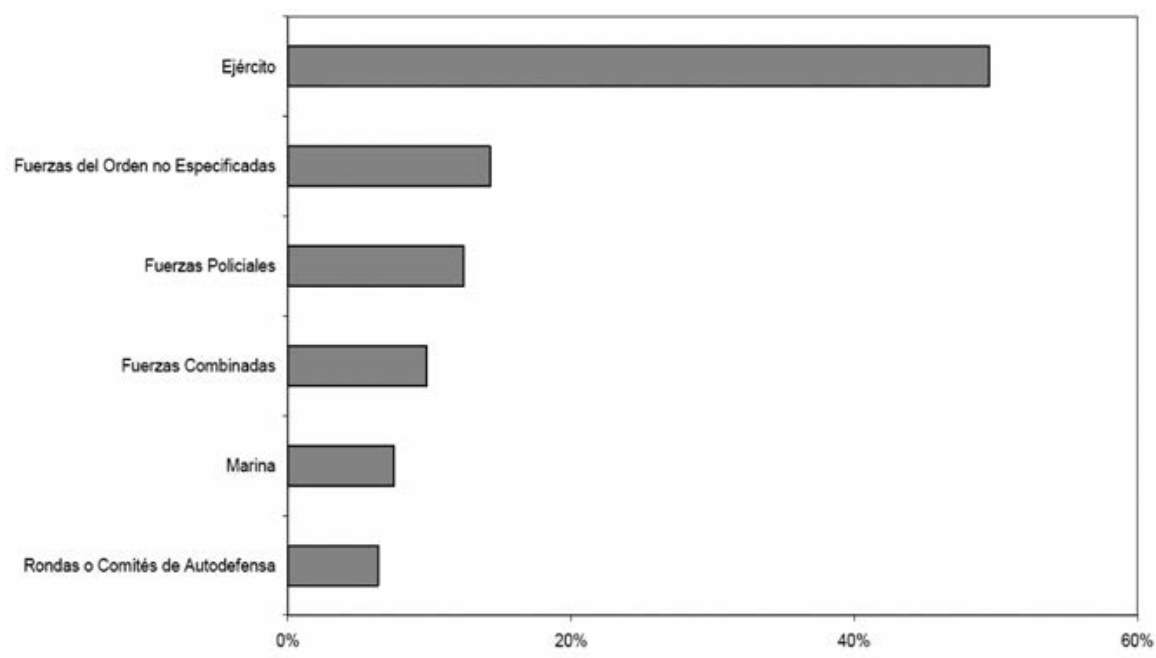

Fuente: Informe Final de la CVR, Las ejecuciones arbitrarias, 2003: 149.

Cuando tales ejecuciones o asesinatos simultáneos y múltiples se realizaban en contra de 5 o más personas en estado de indefensión fueron clasificadas por la CVR como «masacres», es decir una "ejecución arbitraria múltiple o asesinato múltiple cometida con gran crueldad contra personas en estado de indefensión en forma concurrente con otras modalidades de violaciones a los derechos humanos como torturas, mutilaciones $\mathrm{u}$ otras que se encuentren en las mismas circunstancias de tiempo y lugar» (CVR, Las ejecuciones arbitrarias, 2003: 129). A la CVR fueron reportadas 122 masacres cometidas por agentes del Estado y en total 7.334 casos de ejecuciones arbitrarias, cuyas responsabilidades se distribuyeron como demuestra el gráfico $3^{1}$.

1 Por su parte, Sendero Luminoso (SL) fue responsable de asesinatos individuales y colectivos (masacres), cometidos especialmente en la selva y los Andes peruanos como práctica sistemática y generalizada, especialmente en el Departamento de Ayacucho. Según los casos reportados ante la CVR, SL fue el responsable de 11.021 asesinatos y 1.543 desapari- 
Entre las violaciones de derechos humanos cometidas, también las desapariciones forzadas alcanzaron cifras realmente dramáticas. La Dirección General de Búsqueda de Personas Desaparecidas del Ministerio de Justicia y Derechos Humanos (DGBPD), al crear el Registro Nacional de Personas Desaparecidas y Sitios de Entierro (RENADE), en 2018 declaró que las personas desaparecidas entre 1980 y 2000 fueron al menos 20.329. Además, precisó que se desconoce o es incierto el paradero de 13.764 personas, mientras se conoce el paradero de 5.700 personas, pero no se tiene certeza legal de su muerte. La localización, exhumación, identificación y entrega de restos mortales constituyen aún una tarea pendiente para el Estado peruano, que se convierte, con estas últimas cifras lamentablemente aún no definitivas, en uno de los países con más desaparecidos de América Latina (LUM, 2018).

Pero, ¿qué es la desaparición forzada, quiénes las perpetraron en el Perú y según qué modus operandi? La CVR la definió como «la desaparición y privación de libertad de una o más personas cometidas por agentes del Estado o por quienes actúen con su autorización, apoyo o tolerancia, así como por particulares o miembros de organizaciones subversivas, seguido de la falta de información o la negativa a reconocer la privación de libertad o de informar sobre el paradero de la persona» (CVR, Las desapariciones forzadas, 2003: 114). La desaparición forzada de personas fue una práctica generalizada y sistemática empleada como parte de la lucha contrasubversiva, en gran parte del territorio nacional, ejecutándose, según la Comisión Interamericana de Derechos Humanos, «sin perjuicio de que muchas veces afectara a personas que no tenían nada que ver con actividades relacionadas con grupos disidentes» (CIDH, Informe 56/99, párr. 68)².

Por una parte, como demuestra el gráfico 4, el carácter generalizado de esta práctica tuvo lugar especialmente de 1983 a 1985 y de 1989 a 1993. El procedimiento empezaba con la detención de la víctima, generalmente llevada a cabo por agentes encapuchados y armados que trasladaban violentamente al sospechoso a una dependencia policial o militar. En dicho lugar, el detenido se sometía a interrogatorios casi siempre bajo tortura, para confesar información útil para la lucha contrasubversiva; sucesivamente, a veces se ponía en libertad; otras, se ejecutaba arbitrariamente (CVR, Las desapariciones forzadas, 2003: 114). Para destruir las evidencias de las ejecuciones cometidas se desaparecían o

ciones forzadas, lo que eleva la cifra de víctimas atribuidas a este grupo terrorista a un total de 12.564 personas, superando en 1,7 veces el número de muertos y desaparecidos atribuidos a los agentes del Estado, que ascienden a 7.391. Igualmente, SL perpetró un aproximado de 215 masacres, con el propósito de atemorizar a la población y ejercer un extremo control sobre ella, torturando y asesinando masivamente a sus víctimas con técnicas especialmente crueles como degollamientos, lapidaciones y mutilaciones (CVR, Los asesinatos y las masacres, 2003: 20).

2 Según el Estatuto de Roma (ER) que instituyó la Corte Penal Internacional, esta práctica ejecutada de forma generalizada y sistemática constituye un crimen de lesa humanidad (ER, 1999: art. 7, letra i). 
eliminaban los cadáveres mediante mutilación, incineración de restos ${ }^{3}$, arrojando los cuerpos en los ríos u otras zonas inaccesibles, sepultándolos en sitios de entierro o esparciendo las partes de los cuerpos en diferentes lugares para dificultar su identificación ${ }^{4}$.

Por otra parte, la desaparición forzada en el Perú fue una práctica sistemática por la existencia de una estructura de poder organizada que la ideó, organizó y ejecutó según un modus operandi estandarizado para la identificación, selección y procesamiento de las víctimas, así como para la eliminación de sus cuerpos, delegando tales funciones a distintos grupos de agentes militares, policiales, o de civiles. Como indica el gráfico 5, el principal responsable de las desapariciones forzadas resultó ser el Ejército peruano, seguido por las fuerzas policiales, la Marina de Guerra, las Rondas Campesinas y los Comités de Autodefensa.

Para cometer ese tipo de prácticas delictivas, cuyo fin era derrotar el terrorismo de SL y el MRTA, durante el periodo de violencia se crearon diferentes grupos paramilitares en el seno de las fuerzas armadas y policiales. Uno de ellos fue el Grupo Colina, cuyos miembros pertenecían al Servicio de Inteligencia del Ejército peruano (SIE), que «cumplía una política de Estado consistente en la identificación, el control y la eliminación de aquellas personas que se sospechaba pertenecían a los grupos insurgentes o contrarias al régimen del exPresidente Alberto Fujimori, mediante acciones sistemáticas de ejecuciones extrajudiciales

3 En 2016 la Corte Suprema peruana sentenció que Vladimiro Montesinos Torres, Nicolás de Bari Hermoza Ríos, Jorge Enrique Nadal Paiva fueron autores mediatos del delito de desaparición forzada en perjuicio de Martín Javier Roca Casas, Kenneth Ney Anzualdo Castro, Justiniano Najarro Rúa y toda la sociedad. La sentencia confirmó la existencia de sótanos en el edificio conocido como el Pentagonito, en Lima, sede del Servicio de Inteligencia del Ejército (SIE), donde se llevaba a las personas desaparecidas para incinerarlas en hornos crematorios. Con este fallo, el Estado peruano cumple con impartir justicia por la vía judicial interna, tal como la Corte IDH le había ordenado en el caso Anzualdo Castro vs. Perú. Sin embargo, otros puntos muy importantes de dicha sentencia quedan incumplidos, como por ejemplo la búsqueda, localización, exhumación, identificación y entrega de los restos mortales de los desaparecidos a sus familiares (Corte Suprema, 2016).

4 En 2017, la Sala Penal Nacional de la Corte Suprema dictó una sentencia histórica relativa a las violaciones de los derechos humanos realizadas en el cuartel Militar «Domingo Ayarza», más conocido como "Los Cabitos», en Ayacucho. Quedó probado que en los años ochenta, centenares de personas fueron detenidas de forma arbitraria y sometidas a tortura con la finalidad de que confesasen su supuesta afiliación a Sendero Luminoso, para ser finalmente desaparecidas. Además, quedó probado que en "La Hoyada», zona aledaña a "Los Cabitos», se hallaron fosas en las que 109 personas fueron enterradas. En esa localidad también se probó la existencia de un horno crematorio que fue utilizado para incinerar y desaparecer los restos de las víctimas. En ese mismo lugar, a pesar de los enormes obstáculos encontrados, los familiares luchan para que se habilite el Santuario de la Memoria de la Hoyada para poder recordar a sus víctimas. La sentencia finalmente condenó a 23 y 30 años de prisión respectivamente a Pedro Paz Avendaño, Jefe del Destacamento de Inteligencia de la Segunda Infantería, y Humberto Orbegozo Talavera, Jefe de Unidad (Reyes, 2017). 
Gráfico 4. Porcentaje de casos de desaparición forzada por responsable

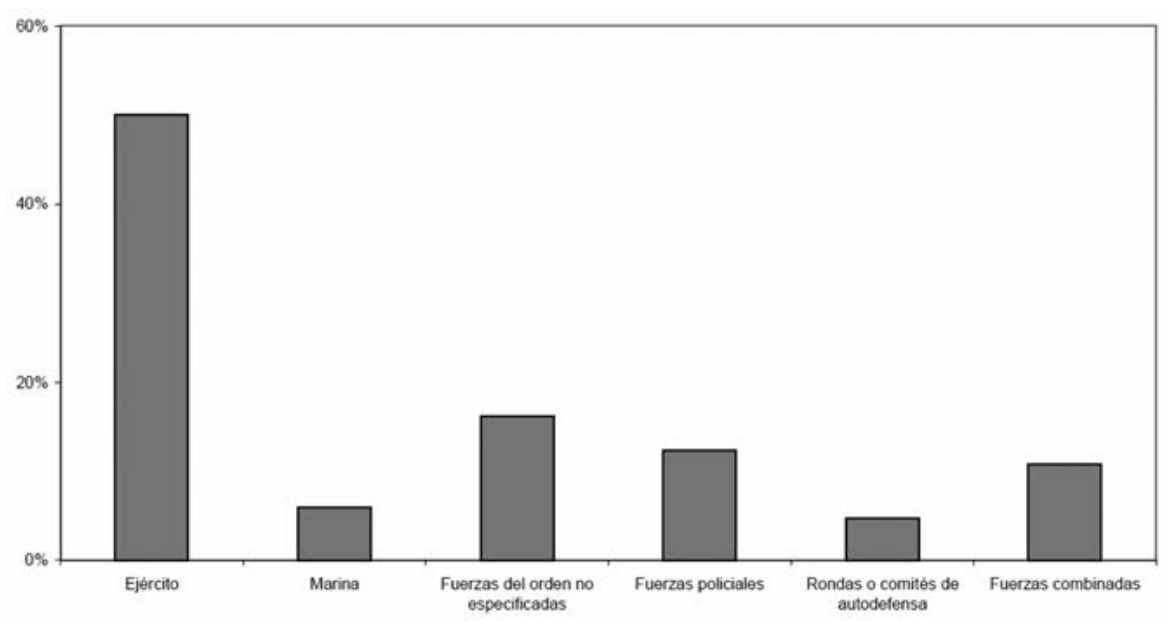

Fuente: Informe final de la CVR, La desaparición forzada, 2003: 81.

Gráfico 5. Número de desapariciones forzadas reportadas a la CVR por año

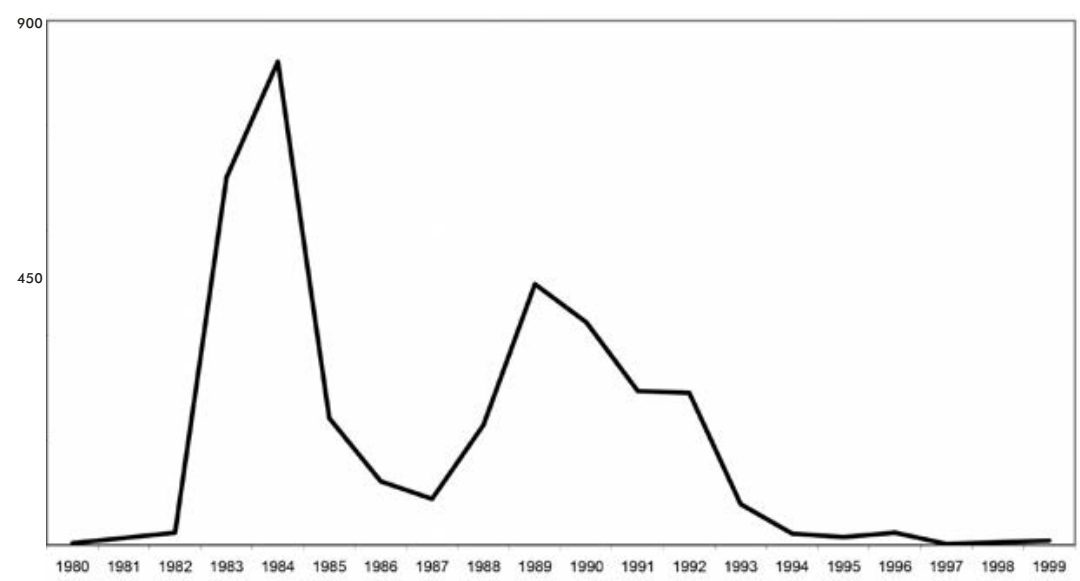

Fuente: Informe final de la CVR, La desaparición forzada, 2003: 81.

indiscriminadas, asesinatos selectivos, desapariciones forzadas y torturas» (Corte IDH, caso La Cantuta vs. Perú, 2006: párr. 40 y 80). El Grupo Colina fue responsable, entre otras acciones, de las masacres de Barrios Altos y de La Cantuta (Jara, 2013), por los cuales el Estado peruano fue condenado por la Corte Interamericana de Derechos Humanos (Corte IDH). Al día de hoy, se pueden considerar 
dos de los casos más emblemáticos por los estándares de tutela de los derechos de las víctimas exigidos por la Corte IDH.

\section{LOS INNUMERABLES INTENTOS DE CONSEGUIR LA IMPUNIDAD EN LOS CASOS BARRIOS ALTOS Y LA CANTUTA}

En este epígrafe examinaremos los casos de Barrios Altos y La Cantuta, sus principales sucesos y su evolución judicial desde la jurisdicción nacional a aquella supranacional, haciendo hincapié en los intentos de conseguir la impunidad por los responsables y, en consecuencia, en la repetida vulneración de los derechos de los familiares de las víctimas antes y después de las sentencias de la Corte IDH. De hecho, el Estado peruano no solo ha violado los derechos humanos de los ciudadanos víctimas de tales sucesos, sino que, después de las sentencias condenatorias de la Corte, si bien ha cumplido con ciertas medidas de reparación, no ha logrado evitar la repetida vulneración de sus derechos, especialmente el de acceso a la justicia, por sucesos de gran calado político y repercusión mediática, que se relatarán a lo largo del artículo.

No obstante, antes de examinar al detalle tales cuestiones, es importante hacer algunas premisas sobre cuáles son las obligaciones internacionales que incumben al Estado peruano ante el Sistema Americano de Derechos Humanos y cuál está siendo el rol de la Corte IDH, que mediante «herramientas prácticas e inmediatas», tal como el control de convencionalidad, está tratando de elaborar un ius commune en el ámbito de la tutela de los derechos humanos en la región (Sagüés, 2010: 451). En específico, trataremos de concretar qué se entiende por derecho de acceso a la justicia según el ordenamiento jurídico peruano y en el respecto de la Convención Americana sobre Derechos Humanos (CADH). En primer lugar, es preciso recordar que el Perú es parte del Sistema Interamericano de protección de los Derechos Humanos por haber suscrito la CADH el 22 de noviembre de 1969, ratificándola el 12 de julio de 1978. Asimismo, el 21 de enero de 1981 el Estado peruano aceptó la competencia contenciosa de la Corte IDH (Ortiz Gaspar, 2012: 5). Por tanto, las sentencias de la Corte Interamericana son de su obligatorio cumplimiento para los Estados parte de la CADH que están obligados «a respetar los derechos y libertades reconocidos en ella y a garantizar su libre y pleno ejercicio» (CADH, 1969, art. 1.1) y a «aprobar las medidas legislativas o de otro carácter que fueren necesarias para hacer efectivos tales derechos» (CADH, 1969, art. 2). De hecho, la obligación de cumplir lo dispuesto en las decisiones de la Corte corresponde a un principio básico del derecho sobre la responsabilidad internacional del Estado, según el cual los Estados deben acatar sus obligaciones convencionales internacionales de buena fe (pacta sunt servanda) dispuesto por el art. 27 de la Convención de Viena sobre el Derecho de los Tratados de 1969 (CIDH, RSCS, Caso Barrios Altos, 2012, fund. 4). 
En segundo lugar, es esencial subrayar que de todos los Estados que ratificaron la $\mathrm{CADH}$, el Perú resulta ser, al día de hoy, el más condenado por la violación de derechos humanos con 29 sentencias firmes de la Corte IDH, la mayoría por hechos cometidos en el marco del periodo de violencia entre 1980 y 2000 (Ugarte Boluarte, 2014). Tales sentencias confirman que el Estado peruano, al cometer asesinatos, masacres y ejecuciones arbitrarias, entre otras prácticas, vulneró principalmente el derecho a la vida. Asimismo, infligiendo torturas y otros tratos crueles, inhumanos o degradantes quebrantó especialmente el derecho a la integridad física y moral; mediante los secuestros y las desapariciones forzadas violó principalmente el derecho a la libertad personal, por llevar a cabo juicios con «jueces sin rostro» vulneró el derecho al debido proceso (Salado Osuna, 2004).

En tercer lugar, es importante definir que el derecho de acceso a la justicia de las víctimas, tal como lo menciona la Corte IDH en las sentencias sobre los referidos casos, está tutelado por los arts. 8.1 y 25.1 de la CADH, los cuales se refieren a los derechos a las garantías judiciales y la protección judicial, respectivamente. Por un lado, el art. 8.1. establece:

Toda persona tiene derecho a ser oída, con las debidas garantías y dentro de un plazo razonable, por un juez o tribunal competente, independiente e imparcial, establecido con anterioridad por la ley, en la sustanciación de cualquier acusación penal formulada contra ella, o para la determinación de sus derechos y obligaciones de orden civil, laboral, fiscal o de cualquier otro carácter (CADH, 1969, art. 8.1).

Por otro lado, el art. 25.1 indica:

Toda persona tiene derecho a un recurso sencillo y rápido o a cualquier otro recurso efectivo ante los jueces o tribunales competentes, que la ampare contra actos que violen sus derechos fundamentales reconocidos por la Constitución, la ley o la presente Convención, aun cuando tal violación sea cometida por personas que actúen en ejercicio de sus funciones oficiales (CADH, 1969, art. 25.1).

En conclusión, el derecho de acceso a la justicia podría encuadrarse en el art. 139.3 de la Constitución Política (CP) peruana que se refiere a la tutela judicial efectiva, estableciendo:

Ninguna persona puede ser desviada de la jurisdicción predeterminada por la ley, ni sometida a procedimiento distinto de los previamente establecidos, ni juzgada por órganos jurisdiccionales de excepción ni por comisiones especiales creadas al efecto, cualquiera sea su denominación (CP, 1993, art. 139.3)5.

5 Sobre el derecho de acceso a la justicia en América Latina véase Brewer-Carías, 2005: 76-100. 
En cuarto lugar, es importante recordar que el control de convencionalidad ejercido por la Corte IDH tiene una doble dimensión: el externo (propio y original) y el interno, que ha sido, sobre todo en las últimas décadas, objeto de un largo y sólido desarrollo en la jurisprudencia de la Corte. El control externo de convencionalidad oficialmente incumbe a la Corte IDH, que lo ejerce con el propósito de apreciar la compatibilidad entre los actos internos (de los Estados miembros de la CADH y que han reconocido la competencia de la Corte IDH) y los convencionales. Sin embargo, la Corte IDH ha ido fomentando, a través de sentencias muy relevantes (entre otras, las que citaremos a continuación) un control interno de convencionalidad, cuya potestad se ha ido reconociendo a determinados órganos jurisdiccionales nacionales para verificar la congruencia de determinados actos internos con la $\mathrm{CADH}$ y con el derecho internacional de los derechos humanos (García Ramírez, 2011: 124-126) ${ }^{6}$. Tal control interno de convencionalidad ha llegado a consolidarse en el escenario latinoamericano con la sentencia emitida por la Corte IDH en la sentencia sobre el caso Almonacid Arellano y otros vs. Chile, del 26 de septiembre de 2006, en la que, resumidamente, se estableció que el poder judicial de los Estados miembros, dentro del marco de vigencia de la $\mathrm{CADH}$, debería ejercer un control de convencionalidad entre las normas jurídicas internas que aplican en los casos concretos y la $\mathrm{CADH}$, teniendo en cuenta también la misma interpretación de dicha convención por parte de la Corte IDH. Sucesivamente, en el caso Trabajadores Cesados del Congreso (Sentencia sobre Aguado Alfaro y otros vs. Perú, del 24 de noviembre de 2006, considerando 128), la Corte IDH especificó, entre otras cuestiones, que los órganos del Poder Judicial deben ejercer, en el marco de sus competencias, no solo un control de constitucionalidad, sino también de convencionalidad, exoficio, entre las normas internas y las convencionales (Sagüés, 2010: 449-451; García Ramírez, 2011: 121).

Aclaradas estas necesarias premisas, es el momento de referirnos a los casos objeto de examen en este artículo, recordando que la masacre de Barrios Altos ocurrió el 3 de noviembre de 1991, durante una fiesta popular que tenía como fin conseguir fondos para reparar un inmueble de Barrios Altos, miembros del Servicio de Inteligencia Nacional (SIN), encapuchados y armados, irrumpieron en el Jirón Huanta 840 en Lima y dispararon contra los asistentes, que consideraron equivocadamente como sospechosos terroristas. Como resultado de ello, 4 personas fueron heridas, quedando una de ellas permanentemente incapacitada y 15 fueron asesinadas ${ }^{7}$ (Corte, caso Barrios Altos vs. Perú, 2001: II letra b).

6 La terminología de «control de convencionalidad» había sido mencionada por primera vez en el caso de la Corte IDH, caso Myrna Mack Chang vs. Guatemala Myrna Mack Chang, en el año 2003, a través del voto concurrente razonado del juez Sergio García Ramírez (Hitters, 2009: 109 y ss.)

7 Víctimas mortales: Placentina Marcela Chumbipuma Aguirre, Luis Alberto Díaz Astovilca, Octavio Benigno Huamanyauri Nolazco, Luis Antonio León Borja, Filomeno León León, Máximo León León, Lucio Quispe Huanaco, Tito Ricardo Ramírez Alberto, 
Aunque la masacre ocurriera en 1991, el 16º Juzgado Penal de Lima inició una investigación formal sobre tales hechos en 1995. Sin embargo, tan pronto se inició la investigación, los tribunales militares interpusieron una petición ante la Corte Suprema reclamando la competencia sobre el caso, alegando que se trataba de oficiales militares en servicio activo. Antes de que la Corte Suprema pudiera resolver el asunto, el Congreso peruano aprobó una Ley de amnistía, la Ley 26479, que exoneraba de toda responsabilidad a los militares, policías, y también a civiles que hubieran ejecutado o participado en violaciones de los derechos humanos entre 1980 y 1995. La Ley 26479 concedió una amnistía a todos los integrantes de las fuerzas de seguridad y los civiles que fueran objeto de denuncias, investigaciones, procedimientos o condenas o que estuvieran cumpliendo sentencias en prisión por violaciones de derechos humanos. Su efecto en el caso específico fue, por tanto, determinar el archivo definitivo de las investigaciones judiciales y así evitar la responsabilidad penal de los responsables de la masacre (Corte IDH, caso Barrios Altos vs. Perú, 2001: II letra i).

De acuerdo con el art. 138 de la Constitución Política del Perú (CP), existiendo en dicho país un sistema mixto de control de constitucionalidad, los jueces tienen el deber de no aplicar aquellas leyes que consideren contrarias a la Constitución y la $\mathrm{CADH}$, puesto que esta última se ha incorporado al bloque de constitucionalidad (Corte IDH, caso Almonacid Arellano et al. vs. Chile, 2006: cons.124). Por lo que, el 16 de junio de 1995, la juez Antonia Saaquicuray del $16^{\circ}$ Juzgado Penal de Lima — una década antes de que el control interno de convencionalidad fuera consolidado por la sentencia de la Corte IDH sobre el caso Almonacid Arellano vs. Chile de 2006 (y las emitidas posteriormente en esa misma línea)-, ejerciendo un control de constitucionalidad y de convencionalidad, decidió que el art. 1 de la Ley 26479 no era aplicable a los miembros del Servicio de Inteligencia Nacional (SIN), imputados por la masacre de Barrios Altos, debido a que la amnistía violaba las garantías constitucionales y las obligaciones internacionales que la CADH imponía al Perú.

Ante la negativa de aplicar la ley de amnistía al caso de Barrios Altos, el Congreso peruano aprobó una segunda Ley, la Ley 26492, cuyo objetivo fue establecer que la amnistía no era revisable en sede judicial y que era de obligatoria aplicación. Además, dicha ley amplió el alcance de la Ley 26479, concediendo una amnistía general para todos los funcionarios militares, policiales o civiles que pudieran ser objeto de procesamientos por violaciones de derechos humanos cometidas entre 1980 y 1995, aunque no hubieran sido denunciadas. Su objetivo era impedir que los jueces se pronunciaran sobre la legalidad o aplicabilidad de la

Teobaldo Ríos Lira, Manuel Isaías Ríos Pérez, Javier Manuel Ríos Rojas, Alejandro Rosales Alejandro, Nelly María Rubina Arquiñigo, Odar Mender Sifuentes Núnez y Benedicta Yanque Churo. Heridos: Natividad Condorcahuana Chicaña, Felipe León León, Tomás Livias Ortega y Alfonso Rodas Alvítez. 
primera ley de amnistía, invalidando lo resuelto por el $16^{\circ}$ Juzgado Penal de Lima e impidiendo decisiones similares en el futuro (Corte IDH, caso Barrios Altos vs. Perú, 2001: II letras k y m).

Es evidente que el contenido de estas disposiciones legislativas colisiona, en primer lugar, con el mismo art. 138 de la CP de 1993, puesto que la Ley trata de prohibir al juez ordinario ejercer un deber que le fue atribuido por la Constitución, es decir llevar a cabo el control difuso de constitucionalidad, no aplicando aquellas leyes que consideren contrarias a las disposiciones constitucionales. En segundo lugar, las disposiciones legislativas colisionan también con el principio de supremacía constitucional, establecido en el art. 51 de la CP de 1993: «La Constitución prevalece sobre toda norma legal, la ley sobre las normas de inferior jerarquía y así sucesivamente [...]».

A raíz de estos hechos, en 1995 los familiares de las víctimas, apoyadas por la Coordinadora Nacional de Derechos Humanos, recurrieron a la Comisión Interamericana de Derechos Humanos (CIDH) en contra del Estado peruano por haber otorgado una amnistía a los agentes responsables de la masacre de Barrios Altos. La comisión, ante la falta de implementación satisfactoria de sus recomendaciones por parte del Estado, elevó el caso ante la Corte IDH. Esta última, examinado el caso, analizó la admisibilidad de las leyes de amnistía, mediante un control de convencionalidad externo (García Ramírez, 2011: 124-126). Asimismo, constató que, además de violar el derecho a la vida (art. $4 \mathrm{CADH}$ ) y a la integridad personal (art. $5 \mathrm{CADH}$ ) de las víctimas, el Estado peruano, mediante los efectos que produjeron las leyes de amnistía, vulneró también el derecho a las garantías judiciales (art. $8 \mathrm{CADH}$ ), el derecho a la protección judicial (art. $25 \mathrm{CADH}) \mathrm{de}$ las víctimas y de sus familiares ${ }^{8}$.

De ahí que, con una sentencia histórica sobre el caso Barrios Altos vs. Perú, el 14 de marzo de 2001 la Corte IDH declaró la inadmisibilidad de las leyes de amnistía y la nulidad de sus efectos, aseverando que los delitos a los cuales se aplicarían son graves crímenes contra la humanidad, con los siguientes argumentos:

Son inadmisibles las disposiciones de amnistía, las disposiciones de prescripción y el establecimiento de excluyentes de responsabilidad que pretendan impedir la investigación y sanción de los responsables de las violaciones graves de los derechos humanos tales como la tortura, las ejecuciones sumarias, extralegales o arbitrarias y las desapariciones forzadas, todas ellas prohibidas por contravenir derechos inderogables reconocidos por el Derecho Internacional de los Derechos Humanos (caso Barrios Altos vs. Perú, Corte IDH, 2001: fund. 41).

8 En el Congreso peruano se llevaron a cabo diversas investigaciones sobre los casos de Barrios Altos y La Cantuta, encontrando numerosos obstáculos que impidieron un mayor esclarecimiento de los hechos (Corte IDH, caso Barrios Altos vs. Perú, 2001: párr. 2 letra f y letra m; Corte IDH, caso La Cantuta vs. Perú, 2006: párr. 80.25 y ss.). 
En cuanto al caso de La Cantuta, con el Decreto Ley n.726 de 8 de noviembre de 1991, el Gobierno peruano legalizó el ingreso de las fuerzas de seguridad en las universidades. A partir del 22 de mayo de 1991, el Ejército estableció un destacamento militar en la Universidad Nacional Enrique Guzmán y Valle, conocida como Universidad La Cantuta (Lima) e impuso en sus instalaciones un toque de queda para contrastar el supuesto control que SL ejercía en la población estudiantil. En la madrugada del 18 de julio de 1992, miembros del Ejército peruano y agentes del Grupo Colina, encapuchados y armados, irrumpieron en las residencias, llevándose a un profesor y 9 estudiantes hacia un destino desconocido9. Dicha operación se consideró como una respuesta al atentado de calle Tarata, llevado a cabo por SL dos días antes en Miraflores (Lima), el 16 de julio de 1992, uno de los ataques más indiscriminados de este grupo terrorista, que causó 25 víctimas mortales y más de 200 heridos (Corte IDH, caso $L a$ Cantuta vs. Perú, 2006, párr. 80.10 y ss.).

El 30 de julio de 1992 los familiares de las víctimas presentaron una petición ante la CIDH por las desapariciones mencionadas. El 4 de febrero de 1993 la Asociación Pro Derechos Humanos (APRODEH) presentó una nueva petición ante la CIDH por las presuntas detención y desaparición de las mismas personas. Ese mismo año, la revista Sí publicó planos con la localización de diferentes fosas clandestinas ubicadas en las localidades de Cieneguilla y Huachipa, en donde la $16^{\circ}$ Fiscalía Provincial Penal de Lima hallaría restos óseos y efectos personales, en su mayoría calcinados, que posiblemente pertenecerían a dos personas de sexo femenino y a tres de sexo masculino, una de ellas mayor de 40 años (por la edad se supuso que podrían ser del profesor Hugo Muñoz Sánchez); fueron encontrados también casquillos de bala, restos de tejido, fibras textiles, cabellos y dos juegos de llaves, las cuales se constató que pertenecían a Armando Richard Amaro Cóndor y Juan Mariños Figueroa. De acuerdo con las evidencias recogidas, los reconocimientos efectuados por los familiares y las pericias realizadas, se confirmó que algunos restos óseos pertenecían a Luis Enrique Ortiz Perea y Bertila Lozano Torres; sin embargo, a pesar de que hayan transcurrido casi treinta años de su desaparición, aún queda pendiente el examen del ADN de los demás restos óseos, que se encargó en el extranjero y cuyo resultado nunca se llegó a conocer (Corte IDH, caso La Cantuta vs. Perú, 2006: párr. 80.30 y ss.).

El 3 de mayo de 1994, después de una larga contienda entre el foro común y el foro militar para determinar a qué jurisdicción correspondía la competencia para juzgar tales hechos, el Consejo Supremo de Justicia Militar (CSJM) dictó sentencia, condenando a miembros del Ejército peruano principalmente por los delitos de abuso de autoridad, secuestro, desaparición forzada de personas en la modalidad de asesinato. Sin embargo, mediante la Ejecutoria Suprema del 16

9 Bertila Lozano Torres, Dora Oyague Fierro, Marcelino Rosales Cárdenas, Juan Gabriel Mariños Figueroa, Heráclides Pablo Meza, Luis Enrique Ortiz Perea, Armando Richard Amaro Cóndor, Robert Édgar Teodoro Espinoza, Felipe Flores Chipana. 
de junio de 1995, se aplicó la Ley de amnistía 26479, dejando sin cargos a los responsables. En relación con la investigación de los posibles autores intelectuales de los hechos, el 11 de mayo de 1994 la Sala de Guerra del CSJM abrió una instrucción por delitos contra la vida, el cuerpo y la salud en la modalidad de homicidio, secuestro, desaparición forzada de personas, entre otros delitos, imputando a diversos miembros del Ejército peruano. Sin embargo, la causa fue archivada por el CSJM por considerar improbados los delitos cometidos.

El 10 de febrero de 2006 la CIDH, ante la falta de implementación satisfactoria por parte del Estado de sus recomendaciones, decidió someter el presente caso a la jurisdicción de la Corte IDH. Esta, examinado el caso, dictó una nueva sentencia histórica, determinando que:

los hechos de La Cantuta, cometidos contra las víctimas ejecutadas extrajudicialmente o desaparecidas forzadamente, constituyen crímenes contra la humanidad que no pueden quedar impunes, son imprescriptibles y no pueden ser comprendidos dentro de una amnistía (Corte IDH, caso La Cantuta vs. Perú, 2006, párr. 225).

La sentencia de la Corte IDH sobre el caso de La Cantuta condenó al Estado peruano por haber violado el derecho a la vida (art. 4.1 CADH), el derecho a la integridad personal (art. 5.1. y 5.2. CADH) y el derecho de la libertad personal (art. $7 \mathrm{CADH}$ ), en perjuicio de las víctimas. Además, la Corte afirmó que el Estado peruano es responsable internacionalmente también por violar el derecho a las garantías judiciales $(8.1 \mathrm{CADH})$ y a la protección judicial de las víctimas (art. $25 \mathrm{CADH}$ ), puesto que en repetidas ocasiones se impidió la investigación, enjuiciamiento y sanción de los responsables de los hechos ocurridos.

En ambas sentencias relativas a los casos Barrios Altos y La Cantuta, la Corte condenó al Estado peruano por incumplir con su obligación de adoptar disposiciones de derecho interno a fin de adecuar su ordenamiento a las disposiciones de la Convención Americana (art. $2 \mathrm{CADH}$ ), al aplicar las leyes de amnistía. En ambas sentencias, por un lado, la Corte subrayó la obligación del Estado peruano de investigar los hechos ocurridos para esclarecer la verdad, recalcando que, especialmente para el caso de La Cantuta, conocer dónde se encuentran los restos mortales constituye una medida de reparación para los familiares de las víctimas y, por tanto, una expectativa que el Estado debe satisfacer. Por estos motivos, ordenó proceder de inmediato a la búsqueda y localización de los demás restos mortales de las víctimas de La Cantuta que siguen desaparecidas, a su identificación y entrega a la brevedad posible a sus familiares, petición que hasta el día de hoy ha quedado desatendida (Corte IDH, caso La Cantuta vs. Perú, 2006: párr. 232). Por otro lado, en ambas sentencias, la Corte ordenó al Estado peruano que se realizaran procesos judiciales internos que permitieran llegar a la asignación de la responsabilidad penal de lo ocurrido, divulgando públicamente los resultados de dicha investigación y de la sentencia (Corte IDH, caso La Cantuta vs. Perú, párr. 237). 
Después de la caída del régimen de Fujimori en 2000 y de la sentencia de Barrios Altos en 2001, siguiendo el mandato de la Corte IDH, fueron activadas nuevas investigaciones de carácter penal en el fuero común, relacionadas con los casos examinados, llegando a condenar a algunos altos mandos de las Fuerzas Armadas pertenecientes al Grupo Colina ${ }^{10}$. Sin embargo, la condena que tuvo mayor impacto político y repercusión mediática fue la del expresidente Alberto Fujimori (Salmón, 2014). El 7 de abril del 2009, después de que la Corte Suprema de Justicia de Chile autorizara su extradición solicitada por el Estado peruano ${ }^{11}$, Fujimori fue condenado por la Sala Penal Especial de la Corte Suprema a 25 años de pena privativa de la libertad por su participación en calidad de autor mediato dentro de un aparato organizado de poder (Grupo Colina) en los delitos de homicidio calificado por alevosía, lesiones graves y secuestro agravado por crueldad, en los casos Barrios Altos y La Cantuta, los secuestros del empresario Samuel Dyer y del periodista Gustavo Gorriti (en adelante «caso de los Sótanos del SIE»), producidos en el marco del autogolpe de Estado del 5 de abril de 1992 (CSJR, caso Fujimori, 2009).

En conclusión, a pesar de los recientes pasos que la jurisdiccional nacional ha dado hacia la sanción de los autores de tales crímenes acatando las sentencias de la Corte IDH, se puede constatar una búsqueda continuada de impunidad por parte de los responsables de tales masacres antes y después del periodo de violencia 1980-2000 como también antes y después de las sentencias de Barrios

10 La Sala Penal Especial de la Corte Suprema en 2010 condenó a Vladimiro Montesinos, capitán del Ejército en Situación Militar de Retiro, asesor de Alberto Fujimori y a otros 19 exmilitares a penas de entre 15 y 25 años por las matanzas de Barrios Altos (1991), El Santa (1992) y por la desaparición del periodista Pedro Yauri (1992). También sentenció a 25 años al Nicolás Hermoza Ríos, exjefe del Comando Conjunto de las Fuerzas Armadas, a Julio Salazar Monroe, exjefe del Servicio de Inteligencia Nacional, a Juan Rivera Lazo, exgeneral del Ejército, al ser considerados, junto con Montesinos, autores intelectuales de tales crímenes de lesa humanidad. La misma pena fue aplicada al jefe del Grupo Colina, Santiago Martín Rivas, y a Carlos Eliseo Pichilingue Guevara, que fueron los ejecutores materiales. La sala encontró culpables de los delitos de homicidio calificado, desaparición forzada y asociación ilícita para delinquir a 19 de los 26 procesados del Grupo Colina ( $E l$ mundo, 2010). Además, la Sala Penal Nacional del Colegiado A, en 2013, condenó a 22 años de cárcel a Juan Vargas Chochoque, Cesar Alvarado Salinas y Ángel Pino Díaz, pertenecientes al Grupo Colina, por los delitos de homicidio calificado y desaparición forzada por el caso La Cantuta, solicitando la búsqueda y la orden de captura de Aldo Velásquez Asencio (El Diario, 2013).

11 Alberto Fujimori salió del país el 13 de noviembre de 2000 a propósito de la cumbre APEC y ya no regresó a Perú. El 19 de noviembre de 2000 envió desde Tokio un fax con su renuncia a la investidura presidencial. El congreso de la República la desestimó y aprobó su vacancia por incapacidad moral. Después de cinco años el expresidente visitó Chile, donde fue detenido por las autoridades de dicho país. Finalmente, el 21 de septiembre de 2007, la Corte Suprema de Chile aprobó la petición de extradición del Perú para juzgarlo por los casos de Barrios Altos y La Cantuta y el «caso de los Sótanos del SIE» (JSIP de la Corte Suprema, 2018: párr. 20). 
Altos y La Cantuta vs. Perú. Dicha impunidad ha vulnerado constantemente los derechos de las víctimas y de sus familiares, especialmente su derecho de acceso a la justicia. A fin de asegurar su tutela, las sentencias de la Corte IDH y sus sucesivas revisiones de cumplimiento han sido fundamentales, puesto que no solo han permitido, entre otras medidas, declarar la inadmisibilidad de las leyes de amnistía sino también examinar la legitimidad del indulto concedido a Alberto Fujimori en 2017 mediante un control interno de convencionalidad, que examinaremos en el próximo epígrafe.

\section{LA REVOCACIÓN DEL INDULTO A ALBERTO FUJIMORI. EL ROL FUNDAMENTAL DE LA CORTE IDH EN LA TUTELA DEL DERECHO DE ACCESO A LA JUSTICIA DE LOS FAMILIARES DE LAS VÍCTIMAS Y EN LA CONSOLIDACIÓN DEL IUS CONSTITUTIONALE COMMUNE MEDIANTE EL CONTROL DE CONVENCIONALIDAD}

Transcurridos ocho años de la condena de Alberto Fujimori, el 24 de diciembre de 2017 el expresidente de la República Pedro Pablo Kuczynski (PPK) le concedió el «indulto y derecho de gracia por razones humanitarias», mediante Resolución Suprema 281-2017-JUS, publicada en una edición extraordinaria del diario oficial El Peruano ${ }^{12}$. El 21 diciembre del 2017, PPK había logrado superar una moción de censura manteniéndose como presidente, después de que el Congreso desestimara la petición de vacancia presentada en su contra por su presunta implicación en el caso Odebrecht $t^{13}$, gracias a la abstención de diez congresistas liderados por Kenji Fujimori del partido Fuerza Popular, que promovió públicamente la concesión del indulto a su padre Alberto (El Comercio, 2017).

La sospecha de que hubo una negociación entre Kenji Fujimori y PPK, cuyo objeto fue votar en contra o abstenerse en la destitución de PPK a cambio de la

12 Antes de esa fecha, la defensa de Fujimori había interpuesto al menos cinco hábeas corpus que fueron desestimados. Según el Tribunal Supremo de Investigación Preparatoria, antes de esa petición de indulto había habido otras 45 peticiones de indulto y conmutación de pena, presentadas por familiares y otras personas: 39 habían sido rechazadas y 6 están en trámite (El Mundo, 2013; JSIP de la Corte Suprema, 2018, párr. 34).

13 El caso Odebrecht está relacionado con un escándalo de corrupción que está afectando a numerosos países de América Latina, cuya protagonista es la empresa constructora Odebrecht (Brasil). Las investigaciones en Perú han demostrado que diversos políticos, funcionarios y empresarios fueron objeto de soborno para favorecer a Odebrecht en la licitación de obras públicas. Además, dicha empresa supuestamente entregó dinero ilícito a favor de las campañas electorales de diversos candidatos presidenciales. No es una casualidad que cuatro de los expresidentes del Perú están siendo investigados por tales hechos, como Alejandro Toledo, Ollanta Humala, PPK y Alán García, que se suicidó el 17 de abril de 2019 cuando la policía estaba dirigiéndose a su vivienda para arrestarlo (El País, 2019; $A B C, 2020)$. 
concesión del indulto a Alberto Fujimori, se confirmó cuando uno de los congresistas de la mayoría parlamentaria de Fuerza Popular, Moisés Mamani, difundió videos, grabados de forma oculta, en los que a los «fujimoristas disidentes» liderados por Kenji Fujimori se ofrecían cargos públicos y presupuesto del Ejecutivo para obras de infraestructura, a cambio de no asistir a la votación de la destitución de PPK o, en el caso de asistir, que se abstuvieran. Por el escándalo que supusieron dichas negociaciones ilegales, PPK renunció a la Presidencia de la República en marzo de 2018 (La República, 2018). La concesión del indulto surtiría efectos en los casos por los que Alberto Fujimori había sido condenado con sentencia firme, como los casos de Barrios Altos y de la Cantuta y el «caso de los Sótanos del SIE»; mientras que el derecho de gracia ${ }^{14}$ surtiría sus efectos en los procesos penales en curso como el caso Pativilca ${ }^{15}$, en el cual es imputado por los delitos de asociación ilícita para delinquir y homicidio calificado.

Sin embargo, gracias a las acciones legales llevadas a cabo por los familiares de las víctimas, el 30 de mayo de 2018 la Corte IDH, en su Resolución de Supervisión de Cumplimiento de Sentencia (RSCS) relativa a los casos Barrios Altos y La Cantuta vs. Perú ${ }^{16}$, se pronunció sobre si el mencionado indulto era compatible con el derecho de acceso a la justicia de los familiares de las víctimas de los referidos casos. En su Resolución, la Corte dispuso que, al fin de comprobar la legitimidad de tal medida, se ejerciera un control de convencionalidad por los jueces y tribunales nacionales y que, tomando en cuenta los estándares internacionales de protección de los derechos humanos, realizaran un examen de proporcionalidad entre el derecho fundamental de acceso a la justicia de las víctimas (y de sus familiares) y los derechos fundamentales a la vida y a la integridad de Fujimori.

La Corte precisó que en su sentencia abordaría solo la legitimidad del indulto por razones humanitarias y no el derecho de gracia, puesto que solo la primera medida es aplicable a los casos de Barrios Altos y La Cantuta, los cuales ya cuentan con una sentencia firme de la Corte Suprema (Lovatón, 2018: 361). Es impor-

14 El derecho de gracia es una facultad del presidente de la República (art. 118 numeral 21 de la CP) ejercida a favor de una persona que está siendo investigada, pero que aún no ha sido condenada. El derecho de gracia extingue la acción penal (art. 78 Código Penal Peruano).

15 Los hechos de este caso ocurrieron el 29 de enero de 1992, cuando el Grupo Colina ejecutó a seis campesinos de la Pampa San José y Caraqueño del distrito de Pativilca, Lima. El 19 de febrero de 2018, el Colegiado B de la Sala Penal Nacional publicó su Resolución 039, en la que resolvió que la Resolución Suprema que concedió el derecho de gracia a Alberto Fujimori carecía de efectos jurídicos para el caso Pativilca, por lo que no se aplicaría el derecho de gracia al expresidente Fujimori y este seguiría siendo procesado. El Procurador ad hoc interpuso recurso de nulidad al considerar que el derecho de gracia fue concedido conforme a la Constitución. Sin embargo, el recurso fue desestimado por la Sala Penal Transitoria de la Corte Suprema el 14 de enero 2020 (La República, 2020).

16 Las sentencias de Revisión de Cumplimiento de la Sentencia en el Caso Barrios Altos fueron ocho emitidas en las siguientes fechas: 22 de noviembre de 2002, 28 de noviembre de 2003, 17 de noviembre de 2004, 22 de septiembre de 2005, 4 de agosto de 2008, 7 de diciembre de 2009, 7 de septiembre de 2012 y la última el 30 de mayo 2018. 
tante subrayar en este caso que, a pesar de que el indulto a Alberto Fujimori afectaría también al "caso de los Sótanos del SIE», por el cual Fujimori también fue condenado por la Corte Suprema en 2009, la Corte IDH solo se pudo pronunciar sobre la legitimidad del indulto en relación al derecho de acceso a la justicia de los familiares de las víctimas de Barrios Altos y La Cantuta, mediante una Resolución de Supervisión de Cumplimiento de las Sentencias (RSCS) relativas a tales casos, puesto que aún estaban pendientes de revisión ante su jurisdicción.

El 3 de octubre de 2018, atendiendo a las peticiones de la Corte IDH, el Juzgado Supremo de Investigación Preparatoria (JSIP) de la Corte Suprema del Perú declaró sin efectos jurídicos la Resolución Suprema 281-2017-JUS que había concedido el indulto por razones humanitarias a Fujimori y ordenó continuar a ejecutar su sentencia de condena. La misma decisión fue confirmada por la Sala Penal Especial de la Corte Suprema el 13 de febrero de 2019.

Una vez introducidas las dos resoluciones de la Corte IDH y de la Corte Suprema peruana, respectivamente, que versan sobre la legitimidad del indulto por razones humanitarias concedido a Fujimori, nos dedicaremos a analizar su contenido en relación al control de convencionalidad que la Corte IDH invocó, excluyendo de nuestro ámbito de estudio la verificación del cumplimiento de los requisitos legales establecidos por el ordenamiento peruano para el otorgamiento del indulto por razones humanitarias.

A tal fin, por un lado, hay que recordar que el control de convencionalidad al cual remite la Corte IDH en su RSCS es obligatorio para los Estados parte de la $\mathrm{CADH}$ y debe ser ejercido internamente por los operadores de justicia según sus respectivas competencias, a fin de interpretar y aplicar el derecho nacional en línea con las obligaciones internacionales del Estado en materia de derechos humanos (Sagüés, 2010: 449-450; Hitters, 2009: 112-113). Como hemos mencionado, en Perú existe un sistema mixto de control de constitucionalidad por lo que, de acuerdo con el art. $138 \mathrm{CP}$, todos los jueces tienen la obligación de ejercer un control no solo de constitucionalidad, sino también de convencionalidad, puesto que la CADH se ha incorporado al bloque de constitucionalidad (JSIP de la Corte Suprema, 2018: párrs. 88 y 111).

Por otro lado, es importante aclarar que el indulto y el derecho de gracia concedidos a Alberto Fujimori son fruto del ejercicio de la facultad atribuida al presidente de la República por el art. 118 (inciso 8 y 21) de «dictar resoluciones, conceder indultos, conmutar penas y ejercer el derecho de gracia en los casos en que la etapa de instrucción haya excedido el doble de su plazo más su ampliatoria» (CP, 1993) ${ }^{17}$. Asimismo, el Reglamento Interno de la Comisión de Gracias Presidenciales especifica que el indulto y derecho de gracia se pueden conceder por razones humanitarias cuando el interno padece «una enfermedad no terminal grave, que se encuentre en etapa avanzada, progresiva, degenerativa e incurable;

17 Los arts. 85 y 89 del Código Penal peruano estipulan, respectivamente, que «la ejecución de la pena se extingue» por el indulto y que "el indulto suprime la pena impuesta». 
y además que las condiciones carcelarias puedan colocar en grave riesgo su vida, salud e integridad $\aleph^{18}$ (Blanco y Mamani, 2018: 57).

Ahora bien, la Corte IDH especificó que el Estado debería remover, de facto y de jure, todos los obstáculos que mantuvieran la impunidad, utilizando todos los medios disponibles para cumplir con su obligación de investigar y, en su caso, sancionar a los responsables de los hechos, evitando la repetición de violaciones tan graves, no pudiendo argüir ninguna ley ni disposición de derecho interno para eximirse de tal orden (Corte IDH, caso La Cantuta vs. Perú, 2006: párr. 226). Asimismo, especificó que los hechos de La Cantuta «constituyen crímenes contra la humanidad que no pueden quedar impunes, son imprescriptibles y no pueden ser comprendidos dentro de una amnistía» (Corte IDH, caso La Cantuta vs. Perú, 2006: párr. 225). Por su parte, en la misma línea de la Corte IDH, el TC peruano había señalado anteriormente que, ante las graves violaciones de derechos humanos, como la ejecución extrajudicial y la desaparición forzada, «[la impunidad] debe ser siempre prevenida y evitada, puesto que anima a los criminales a la reiteración de sus conductas, sirve de caldo de cultivo a la venganza y corroe dos valores fundantes de la sociedad democrática: la verdad y la justicia» (STC, caso Genaro Villegas Namuche, 2004: fund. 23).

A pesar de que se valoraran positivamente las decisiones internas emitidas a partir de 2009 a fin de cumplir con dichas obligaciones como la condena de Fujimori, en su RSCS la Corte encontró necesario recordar que «la ejecución de la pena también forma parte de dicha obligación y que durante la misma no se deben otorgar beneficios de forma indebida que puedan conducir a una forma de impunidad. Asimismo, la ejecución de las sentencias es parte integrante del derecho al acceso a la justicia de las víctimas» (Corte IDH, RSCS, 2018: párr. 30).

A tal propósito, la Corte IDH señaló que la concesión del indulto por razones humanitarias a Alberto Fujimori no solo incumpliría con la obligación de investigar, juzgar y, de ser el caso, sancionar tales violaciones, sino que chocaría con importantes estándares internacionales de protección de los derechos humanos ${ }^{19}$. Refiriéndose a una amplísima jurisprudencia internacional y regional, la Corte afirmó que, efectivamente, existe una tendencia creciente en el derecho internacional de los derechos humanos y el derecho penal internacional en evitar que las condenas impuestas por tribunales penales por graves violaciones de los derechos humanos sean perdonadas o extinguidas mediante decisiones discrecionales de los Poderes Ejecutivo o Legislativo (Corte IDH, RSCS, 2018: párrs. 36-45). Por estas razones, sugirió que en el control interno de convencionalidad se valorara si la aplicación del indulto por razones humanitarias estaría produciendo «una afectación innecesaria y desproporcionada al derecho de acceso a la justicia de las víctimas de tales violaciones y sus familiares, en cuanto a la proporcionalidad de

18 Aprobado mediante Resolución Ministerial 0162-2010-JUS (art. 31 letra b).

19 Sobre la problemática del indulto humanitario a Fujimori en el supuesto de crímenes de lesa humanidad véase también Merzarina García, 2014: 101-118. 
la pena impuesta en el proceso judicial y su ejecución» (Corte IDH, RSCS, 2018: párr. 45). Por lo tanto, se aprecia cómo la Corte indicó a la jurisdicción nacional utilizar como criterios de interpretación la necesidad y la proporcionalidad para dirimir la posible tensión entre el derecho de acceso a la justicia de las víctimas y los derechos a la vida e integridad del condenado (Lovatón, 2018: 266).

Tal como sostienen Blanco y Mamani (2018: 57), la Corte IDH, amparándose en el art. 30 de la $\mathrm{CADH}^{20}$ había afirmado que los derechos contemplados en la $\mathrm{CADH}$ no son absolutos, pero que eventuales restricciones de tales derechos solo estarían permitidas si fueran sujetas a determinadas condiciones, entre ellas la necesidad y la proporcionalidad, a fin de garantizar la plena vigencia de otros derechos y valores dentro de una sociedad democrática ${ }^{21}$. En el caso del indulto otorgado a Alberto Fujimori, en cuanto a la necesidad, la Corte recordó que existe la obligación de evaluar todas las posibles medidas posibles para alcanzar el fin legítimo, restringiendo con la menor lesividad posible otros derechos: en este caso, el derecho al acceso de la justicia de las víctimas. ¿¿Representaba el indulto humanitario la medida necesaria y menos lesiva para alcanzar el fin perseguido o existían otras alternativas menos restrictivas del derecho de acceso a la justicia de las víctimas? ¿No hubiera sido posible adoptar medidas menos lesivas como, por ejemplo, mejorando las condiciones carcelarias, brindándole la asistencia médica necesaria dentro de las instalaciones carcelarias o trasladándole a otro centro médico sin que fuera contemplada su liberación?

En cuanto a la proporcionalidad de la medida, la Corte concretó que tratándose de graves violaciones de los derechos humanos resultaría necesario tomar en cuenta, además de la situación de salud del condenado, otros factores o criterios importantes tales como: que se haya cumplido una parte considerable de la pena privativa de libertad y se haya pagado la reparación civil impuesta en la condena, la conducta del condenado respecto al esclarecimiento de la verdad, el reconocimiento de la gravedad de los delitos perpetrados y su rehabilitación y los efectos que su liberación anticipada tendría a nivel social y sobre las víctimas y sus familiares $^{22}$ (Corte IDH, RSCS, 2018: párr. 57). Por tanto, la Corte IDH solicitó a la jurisdicción nacional examinar si existiera otra medida distinta al indulto que permitiera proteger la vida e integridad de Fujimori y que, a la vez, fuera la menos lesiva y que restringiera lo menos posible el derecho de acceso a la justicia de las

20 «Las restricciones permitidas, de acuerdo con esta Convención, al goce y ejercicio de los derechos y libertades reconocidas en la misma, no pueden ser aplicadas sino conforme a leyes que se dictaren por razones de interés general y con el propósito para el cual han sido establecidas» (CADH, 1969, art. 30).

21 Véase al menos los siguientes casos: caso Atala Riffo y niñas vs. Chile, 24 de febrero de 2012, párr. 164 y el caso Escher y otros vs. Brasil, 6 de julio de 2009, párr. 116.

22 El día de recibir el indulto, Alberto Fujimori había cumplido 10 años, 10 meses y 2 días de los 25 años a los que fue condenado. Asimismo, al momento del indulto no había pagado monto alguno de la reparación civil impuesta. No ha reconocido su culpabilidad, no ha pedido perdón a las víctimas ni se ha mostrado arrepentido de los hechos cometidos (JSIP de la Corte Suprema, 2018, párr. 11). 
víctimas y de sus familiares, acorde con el principio de proporcionalidad (Corte IDH, RSCS, 2018: párr. 68).

A partir de dicha RSCS, el Juzgado Supremo de Investigación Preparatoria (JSIP) de la Corte Suprema del Perú aplicó el control de constitucionalidad y convencionalidad y, mediante la Resolución 10 del 3 de octubre de 2018, dejó sin efecto el indulto otorgado por razones humanitarias a Fujimori, ordenando su vuelta a prisión. Además de observar serias irregularidades en el cumplimiento de los requisitos estipulados en el derecho peruano para otorgar dicho indulto, las cuales no son materia de estudio del presente artículo, el control de constitucionalidad y de convencionalidad llevado a cabo en sede nacional se sustentó en los mismos argumentos claves de la sentencia de la Corte IDH.

Por una parte, el JSIP sostuvo que el indulto es incompatible con las obligaciones internacionales que el Perú ha asumido, más aún si se toman en consideración los pronunciamientos del TC donde señala que el indulto no procede en caso de delitos de lesa humanidad (JSIP de la Corte Suprema, 2018: párr. 299). Efectivamente, el TC peruano en la sentencia 0012-2010 afirmó que: «existen ciertos actos delictivos que alcanzan tal nivel de violación de la dignidad del ser humano que [...] la posibilidad de adoptar medidas que impidan la efectiva sanción se encuentra proscrita» (STC, 2010, caso Más de 5000 ciudadanos c. Congreso de la República: párr. 46).

El JSIP, por tanto, llegó a afirmar que «en cuanto al indulto en el Perú, en casos de delitos de lesa humanidad, no procede su concesión [...] y durante la ejecución de la pena, no se deben otorgar beneficios en forma indebida que puedan conducir a una forma de impunidad» (JSIP de la Corte Suprema, 2018: párrs. 130 y 287). Asimismo, añadió que [el indulto] es una institución jurídica que faculta al Presidente de la República perdonar una condena penal, impuesta por los órganos jurisdiccionales competentes del Poder Judicial para delitos de lesa humanidad, lo que afecta el derecho de acceso a la justicia de las víctimas» (JSIP de la Corte Suprema, 2018: párr. 288).

Por último, estableció que el indulto concedido a Fujimori no superaba el examen de proporcionalidad en cuanto al principio de necesidad, puesto que existen otras medidas que hubieran resultado menos lesivas del derecho de acceso a la justicia de las víctimas que a la vez hubieran podido proteger el derecho a la salud y a la integridad física del condenado (JSIP de la Corte Suprema, 2018: párr. 320). Finalmente, la Sala Penal Especial de la Corte Suprema, el 13 de febrero de 2019, ratificó el control de constitucionalidad y de convencionalidad en sede nacional sobre el indulto concedido a Alberto Fujimori.

En consecuencia, después de haber examinado tanto los principales hechos que se han ido aconteciendo a lo largo de las últimas décadas como las diferentes sentencias supranacionales y nacionales emitidas sobre los Casos Barrios Altos y La Cantuta, podríamos llegar a dos principales conclusiones: la primera se refiere a la clara tendencia de las decisiones de la Corte IDH en la creación de un ius commune en el ámbito de la tutela de los derechos humanos en América Latina (Morales Antoniazzi: 
2017); la segunda es inherente al creciente diálogo, aunque en ocasiones no siempre tan proficuo, entre la Corte IDH y las Cortes nacionales (Bogdandy, 2011).

Por lo que se refiere a la primera cuestión, es indudable que, a pesar de los intentos de conseguir la impunidad puestos en marcha por los responsables de las masacres de Barrios Altos y La Cantuta, gracias a las emblemáticas sentencias de la Corte IDH y sus posteriores supervisiones, se ha logrado tutelar el derecho de acceso a la justicia de las víctimas frente a las repetidas e inaceptables vulneraciones sufridas. Este logro es, sin duda, fruto de la «vocación transformadora», en palabras de García Ramírez y Morales Sánchez (2020:11), que la Corte IDH ha asumido en estas últimas décadas, «emitiendo una jurisprudencia, creciente y variada, que pretende introducir en la región de su competencia cambios sustanciales en el orden jurídico interno y en la práctica de los Estados americanos, especialmente los que forman parte de América Latina", a fin de establecer criterios vinculantes en materia de derechos humanos aplicables a los Estados que han adoptado la $\mathrm{CADH}$ y reconocido la competencia contenciosa de la Corte. Lo confirma el hecho de que su jurisprudencia, sobre todo en los casos relativos a las violaciones de los derechos humanos cometidas durante los periodos de violencia que han interesado no solo Perú, sino a la entera región, ha fijado importantes estándares internacionales que deben satisfacerse por los Estados nacionales, para tutelar el derecho a una reparación integral, el derecho a la justicia y el derecho a la verdad de las víctimas y de sus familiares, entre otros (Quinche Ramírez, 2009). Dichos criterios estándares, que se han logrado establecer principalmente mediante el control de convencionalidad, responden a un objetivo superior (definido por la escuela del Max Planck Institute for Comparative Public Law and International Law como «la creación un Ius Constitutionale Commune), que se basa principalmente en tres pilares: una concepción integral de los derechos fundamentales, una concepción social de la democracia y una concepción participativa de la jurisdicción constitucional (Arango, 2017: 179-191).

Es aquí que se plantea la segunda cuestión a la que nos referíamos anteriormente: el objetivo de la Corte IDH de crear un Ius Constitutionale Commune ha permitido un vínculo muy estrecho y una creciente interacción entre los jueces nacionales e internacionales, tal como lo ha demostrado el análisis de las sentencias que han llevado a la revocación del indulto concedido a Alberto Fujimori, llevando a concebir al derecho internacional de los derechos humanos como un modelo multinivel de tutela de los derechos humanos en la región (Andrea Acosta, 2017: 371). Por tanto, tal como García Ramírez afirma, el control de convencionalidad «favorece y fertiliza el diálogo jurisdiccional interno e internacional. Contribuye a erigir, detallar, enriquecer e impulsar la cultura jurídica común, conforme al proyecto favorecedor del ser humano y conductor del poder público» (2011:129).

\section{CONCLUSIONES}

Este artículo se ha ocupado de examinar cómo el derecho de acceso a la justicia de las víctimas de los casos Barrios Altos y La Cantuta en Perú, ha sido 
incesantemente vulnerado por los responsables de tales violaciones de los derechos humanos. Durante el periodo de violencia de 1980 a 2000, dicha vulneración se ha materializado, en buena medida, en la «ausencia de una voluntad estatal destinada a investigar y sancionar con penas adecuadas a la gravedad de los delitos cometidos a los responsables [...]» de diferentes crímenes sistemáticos y generalizados perpetrados en el país, como la desaparición forzada y las ejecuciones extrajudiciales, entre otros (STC, 2004, caso Santiago Martín Rivas, párr. 83. ii). Asimismo, la aprobación de las referidas leyes de amnistía, en los años noventa, trató de obstaculizar la asignación de responsabilidades penales a los agentes del Estado que hubieran cometido violaciones de los derechos humanos durante el periodo de violencia. En el periodo del postconflicto, se siguió vulnerando el derecho de acceso a la justicia de los familiares de las víctimas, por ejemplo, con la concesión del indulto por razones humanitarias al expresidente Alberto Fujimori. Sin embargo, gracias a los tratados internacionales que el Perú ha suscrito en materia de derechos humanos, tal como la $\mathrm{CADH}$, algunos de los intentos de conseguir la impunidad por parte de los responsables han sido frustrados, mediante el control de convencionalidad ejercido y/o invocado por la Corte IDH. Dicho control de convencionalidad ha sentado algunos precedentes muy importantes a favor de la tutela de los derechos de los familiares de las víctimas, frente a medidas estatales que impedían la investigación, el juicio y la eventual sanción de los responsables de graves violaciones de los derechos humanos y/o crímenes de lesa humanidad. Entre tales precedentes podemos mencionar, en primer lugar, la inadmisibilidad de las mencionadas leyes de amnistía (CIDH, caso Barrios Altos vs. Perú, 2001), fruto de un control de convencionalidad externo llevado a cabo por la Corte IDH y, en segundo lugar, el examen de la legitimidad de medidas como el indulto por razones humanitarias concedido a Alberto Fujimori (CIDH, RSCS, 2018), fruto de un control de convencionalidad interno a los que fueron llamados a responder los jueces nacionales, revocando la medida otorgada. El examen de la reciente jurisprudencia supranacional y nacional sobre los casos mencionados nos confirma, una vez más, la «vocación transformadora de la Corte IDH» en la creación de un ius constitutionale commune en el ámbito de la tutela de los derechos humanos en América Latina (Morales Antoniazzi, 2017) que, en consecuencia, lleva a favorecer un creciente diálogo entre la Corte IDH y las Cortes nacionales (Bogdandy, 2011). Sin embargo, a pesar de los pasos dados hacia la garantía del derecho de acceso a la justicia en los casos Barrios Altos y La Cantuta, la deuda que el Estado peruano y la comunidad internacional mantienen con todas las víctimas del periodo de violencia que va de 1980 a 2000 es indudablemente altísima.

\section{Bibliografía}

Andrea Acosta, P. (2017). Ius Commune interamericano. Brevísimas notas sobre el concepto de diálogo. En A. Von Bogdandy, M. Morales Antonazzi y E. Ferrer 
McGregor. Ius Constitutionale Commune en América Latina. Textos básicos para su comprensión (pp. 371-384). Heidelberg: Max Planck Institute.

Arango, R. (2017). Fundamentos del Ius Constitutionale Commune en América Latina. En A. Von Bogdandy, M. Morales Antonazzi y E. Ferrer McGregor. Ius Constitutionale Commune en América Latina. Textos básicos para su comprensión (pp. 179-192). Heidelberg: Max Planck Institute.

Blanco, C. y Mamani, F. (2018). Las gracias presidenciales a Alberto Fujimori: un análisis desde el Derecho Internacional de los Derechos Humanos. Ius et Veritas, 57, 86-104. Disponible en: https://doi.org/10.18800/iusetveritas.201802.005.

Bogdandy, A. von (2011). Hacia un nuevo derecho público. Estudios de derecho público comparado, supranacional e internacional. México: Universidad Nacional Autónoma de México; Instituto de Investigaciones Jurídicas.

Brewer Carías, A. (2005). Mecanismos Nacionales de Protección de los Derechos Humanos (Garantías judiciales de los derechos humanos en el derecho constitucional comparado latinoamericano). San José de Costa Rica: Instituto Interamericano de Derechos Humanos.

Degregori, C. I. (2014). Heridas abiertas, derechos esquivos. Derechos humanos, memoria y Comisión de la Verdad y Reconciliación. Lima: Instituto de Estudios Peruanos.

García Ramírez, S. (2011). El control judicial interno de convencionalidad. Revista del Instituto de Ciencias jurídicas de Puebla, 5 (28), 123-159. Disponible en: https://doi.org/10.35487/rius.v5i28.2011.68.

García Ramírez, S. y Morales Sánchez, M. (2020). Vocación transformadora de la jurisprudencia interamericana. Anuario Iberoamericano de Justicia Constitucional, 24 (1), 11-49. Disponible en: https://doi.org/10.18042/cepc/aijc.24.01.

Hitters, J. C. (2009). Control de constitucionalidad y control de convencionalidad. Comparación (Criterios fijados por la Corte Interamericana de Derechos Humanos. Revista de Estudios Constitucionales, 7 (2), 109-128. Disponible en: https://doi.org/10.4067/S0718-52002009000200005.

Jara, U. (2013). Ojo por ojo. Lima: Planeta.

Lovatón Palacios, D. (2018). Control de convencionalidad en sede nacional que dejó sin efecto el «indulto humanitario» otorgado al expresidente peruano Alberto Fujimori. Lima: Pontificia Universidad Católica del Perú.

Merzarina García, S. (2014). La problemática del indulto humanitario en el supuesto de crímenes de lesa humanidad: el caso Fujimori. Ars Boni et Aequi, 10 (1), 101-118.

Morales Antonazzi, M. (2017). Interamericanización como mecanismo del Ius Constitutionale Commune en derechos humanos en América Latina. En A. von Bogdandy, M. Morales Antonazzi y E. Ferrer McGregor, Ius Constitutionale Commune en América Latina. Textos básicos para su comprensión (pp. 417-456). Heidelberg: Max Planck Institute.

Ortiz Gaspar, D. (2012). ¿Cómo viene cumpliendo el Perú las sentencias expedidas por la Corte Interamericana de Derechos Humanos? Reflexiones a propósito de una posible sentencia condenatoria por el caso «Chavín de Huántar». Revista Gaceta Constitucional, 49, 1-19. 
Ortiz Perea, G. (2017). Hasta encontrarlos. La identidad como derecho: retos y lecciones en la búsqueda de los desaparecidos en Perú. Revista Memoria del IDEHPUCP, 23.

Quinche Ramírez, M. (2009). El control de convencionalidad y el sistema colombiano. Revista Iberoamericana de Derecho Procesal Constitucional, 12, 163-190.

Sagüés, N. P. (2010). El "control de convencionalidad» como instrumento para la elaboración de un ius commune interamericano. En A. von Bogdandy, M. Morales Antonazzi y E. Ferrer McGregor (coords.). La justicia constitucional y su internacionalización. ¿Hacia un ius constitutionale commune en América Latina? (pp. 403-430). México: Universidad Nacional Autónoma de México; Instituto de Investigaciones Jurídicas; Instituto Iberoamericano de Derecho Constitucional.

Salado Osuna, A. (2004). Los casos peruanos ante la Corte Interamericana de Derechos Humanos. Trujillo: Normas Legales.

Salmón, E. (2014). La condena a Alberto Fujimori y el derecho internacional de los derechos humanos: un capitulo fundamental de la lucha contra la impunidad en Perú. Bogotá: Universidad Externado de Colombia. Disponible en: https://doi. org/10.2307/j.ctv13vdh2q.

Ugarte Boluarte, R. (2014). Los derechos humanos en el Perú: una mirada al cumplimiento de las sentencias supranacionales dictadas por la Corte IDH vs. el Perú. Revista Lex, 12, 14. Disponible en: https://doi.org/10.21503/lex.v12i14.636.

\section{Artículos y noticias de periódicos}

ABC (2020). Keiko Fujimori regresa a prisión por blanqueo de dinero y obstrucción a la Justicia. $A B C, 29-1-2020$.

La República (2018). PPK renunció a la presidencia de la República tras escándalo por «keikovideos». La República, 21-3-2018.

La República (2020). Alberto Fujimori: Corte Suprema ordena que siga siendo procesado por matanza de Pativilca. La República, 13-1-2020.

El Comercio (2017). PPK le otorgó indulto humanitario a Alberto Fujimori. El Comercio, 25-12-2017.

El Mundo (2010). Montesinos, exasesor presidencial peruano, recibe 25 años de cárcel. El Mundo, 2-10-2010.

\section{Artículos de opinión}

Lugar de la Memoria, la Tolerancia y la Inclusión Social (LUM) (2018). Presentan lista del Registro Nacional de Personas Desaparecidas y Sitios de Entierro (Renade). LUM, 24-4-2018. Disponible en: https://bit.ly/3vR2pBS.

Reyes, V. (2017). Justicia para las víctimas de Los Cabitos, un análisis del fallo. IDEHPUCP, 21-8-2017. Disponible en: https://bit.ly/3vMrwW8. 


\section{Informes}

Comisión de Derechos Humanos (2012). Plan Regional de investigaciones antropológico forenses para Ayacucho, estrategias de investigación y lineamientos generales. Ayacucho: COMISEDH.

Comisión de la Verdad y Reconciliación (2003). Informe Final de la Comisión de la Verdad y la Reconciliación. Lima: Comisión de la Verdad y Reconciliación.

Comisión Interamericana de Derechos Humanos (1999). Informe 56/99. Casos Eudalio Lorenzo Manrique y otros. San José de Costa Rica: Corte Interamericana de Derechos Humanos.

\section{Jurisprudencia}

Caso Almonacid Arellano et al. vs. Chile. (Sentencia Corte IDH, 26 de septiembre de 2006).

Caso Anzualdo Castro vs. Perú (Sentencia Corte IDH, 22 de septiembre de 2009).

Caso Atala Riffo y niñas vs. Chile (Sentencia de la Corte IDH, 24 de febrero de 2012).

Caso Barrios Altos vs. Perú (Sentencia Corte IDH, 14 de marzo de 2001).

Caso Condena Alberto Fujimori (Sentencia Corte Suprema de Justicia de la República. Sala Penal Especial, Expediente No. A. V.19-2001, Perú, 7 de abril de 2009).

Caso Escher y otros vs. Brasil (Sentencia de la Corte IDH, 6 de julio de 2009).

Caso Genaro Villegas Namuche (TC del Perú, Expediente No 2488-2002-HC/TC de 18 de marzo de 2004).

Caso Indulto Alberto Fujimori. Resolución sobre el Control de Convencionalidad (Sentencia JSIP de la Corte Suprema de Justicia, Perú, 3 de octubre de 2018).

Caso La Cantuta vs. Perú (Sentencia Corte IDH, 29 de noviembre de 2006).

Caso Más de 5000 ciudadanos c. Congreso de la República (TC del Perú, Expediente 0012-2010-PI/TC, del 11 de noviembre de 2011).

Caso Santiago Martín Rivas (TCl del Perú, Expediente 4587-2004-AA/TC del 29 de noviembre de 2005).

Caso Sótanos del SIE (Sentencia Corte Suprema de Justicia, Perú, 2016). Disponible en: https://doi.org/10.51378/eca.v71i746.3188.

Caso Trabajadores Cesados del Congreso (Sentencia Corte IDH sobre Aguado Alfaro y otros vs. Perú, del 24 de noviembre de 2006).

Casos Barrios Altos y La Cantuta (Resolución de Revisión de Cumplimiento de Sentencias Corte IDH, 30 de mayo de 2018).

\section{Tratados internacionales}

Organización de Estados Americanos (1969). Convención Americana Sobre los Derechos Humanos. San José de Costa Rica: Organización de Estados Americanos.

Corte Penal Internacional (1999). Estatuto de Roma de la Corte Penal Internacional. Roma: Corte Penal Internacional. 